\title{
It's for the Greater Good: Perspectives on Maltreatment during Labor and Delivery in Rural Ghana
}

\author{
Jamila Yakubu1, Dana Benyas², Sarah Vandy Emili3 , Ebenezer Amekah ${ }^{3}$, Richard Adanu4, \\ Cheryl A. Moyer ${ }^{2}$ \\ ${ }^{1}$ University of Michigan, School of Public Health, Ann Arbor, USA \\ ${ }^{2}$ University of Michigan Medical School, Global REACH, Ann Arbor, USA \\ ${ }^{3}$ Ghana Health Service, Central Region, Accra, Ghana \\ ${ }^{4}$ University of Ghana, School of Public Health, Accra, Ghana \\ Email: jyakubu@med.umich.edu, dbenyas@umich.edu, vandymail@yahoo.com, amekah2000@yahoo.ca, \\ rmadanu@yahoo.com, camoyer@med.umich.edu
}

Received 27 March 2014; revised 25 April 2014; accepted 3 May 2014

Copyright (C) 2014 by authors and Scientific Research Publishing Inc.

This work is licensed under the Creative Commons Attribution International License (CC BY).

http://creativecommons.org/licenses/by/4.0/

(c) (i) Open Access

\section{Abstract}

Aim: Encouraging women to deliver in facility settings is one strategy to improve maternal and neonatal outcomes in the developing world. However, in much of sub-Saharan Africa, fewer than half of pregnant women deliver in health facilities. Fear of maltreatment during labor and delivery has been shown to be one barrier to facility delivery, yet previous studies have focused solely on reports from women, rarely seeking insights from practicing midwives. Method: All seven practicing midwives from a rural hospital in Ghana and ten pregnant women seeking antenatal care from the same hospital were recruited to participate in in-depth interviews regarding their perceptions of care during labor and delivery. A semi-structured interview tool and qualitative field interviewing approach were utilized. All interviews were audio taped, transcribed, and analyzed using NVivo 9.0. Results: Respondents described situations that precipitate abuse during facility deliveries, yet not all abuse was seen as acceptable. Two overarching themes emerged: 1) The interaction between midwives and their patients is analogous to a mother/daughter relationship, including both a knowledge imbalance and the need for disciplinary action when necessary; and 2) Midwives feel a strong sense of responsibility for the delivery outcomes and as a result, they will do whatever it takes to deliver a live baby to a healthy mother. Hitting, yelling, and neglecting women were reported as common occurrences in the labor and delivery ward. However, each was undertaken to encourage women to do what was needed to deliver safely. Conclusion: These findings suggest that the issue of patient maltreatment in low-resource labor and delivery settings is complex and may be undertaken in what is perceived to be the laboring woman's best interest. 
The exploration of alternative strategies to facilitate labor and delivery is warranted, as well as the provision of adequate support and resources for practicing midwives in rural settings.

\title{
Keywords
}

\author{
Maltreatment, Midwives, Pregnancy, West Africa, Delivery Care, Developing Countries
}

\section{Introduction}

Almost half of the pregnancy-related deaths in the world are from Sub-Saharan Africa [1]. It is estimated that each year, approximately four million African women, newborns, and infants would survive if known interventions were delivered to $90 \%$ of families [2]. One strategy for reducing maternal and neonatal mortality in low resource countries has been to encourage women to deliver in a health facility with the assistance of a skilled birth attendant [3].

Despite the known medical advantages to delivering in a facility with a skilled birth attendant, many women still do not seek such care. The most recent Demographic and Health Survey (DHS) in Ghana suggested that a skilled birth attendant does not supervise $40 \%$ of births and $43 \%$ of deliveries occur outside a health care facility [4]. Previous research suggests that the treatment women receive when delivering in a facility may serve as a deterrent to facility delivery. Patients describe midwives yelling, acting impatient, not being helpful, or being too harsh to women in labor or during delivery [5] [6]. In some settings, there is an assumption that the labor and delivery experience may be accompanied by neglect and physical and verbal abuse [7]. In one study in northern Ghana, women, grandmothers, household heads, compound heads and even health care providers themselves acknowledged physical and verbal abuse occurring during facility deliveries [6]. Women reported fear of abuse sometimes leading to delays in care seeking [8].

Yelling, hitting, and engaging in disrespectful care has been well documented by patient accounts. Current research under-represents the perspective of midwives, with the notable exception of Abraham, Jewkes, and Mvoin in South Africa who interviewed midwives about their experiences as providers [7]. Those researchers posited that the social status disparity between patients and midwives causes midwives to act in ways that reinforce the social distance between them, including providing disrespectful care.

This study set out to explore the attitudes, beliefs, and self-reported behaviors of a small group of midwives in Ghana to improve understanding of maltreatment during facility delivery. Interviews were designed to explore perspectives on the frequency, severity, and root causes of maltreatment. In addition, pregnant women seeking antenatal care from the same facility where the midwives practice were also interviewed in order to determine overarching themes pervasive between both groups.

\section{Methods}

\subsection{Setting}

All data were collected from May to July 2012 at a small Catholic hospital in the Central Region of Ghana. The hospital is a 135-bed facility that provides medical, surgical, and trauma services in addition to specialized services in obstetrics and gynecology. It also serves as a referral hospital for the health centers and maternity homes in its district. In 2012, the hospital recorded 1404 spontaneous vaginal deliveries (SVDs) and 526 cesarean sections $(\mathrm{C} / \mathrm{S})$. The hospital is staffed by three doctors and seven midwives, and the labor ward has three beds attended by one midwife on duty and supporting staff.

\subsection{Study Design}

This cross-sectional, qualitative study was conducted utilizing semi-structured interview guides for in-depth interviews with both pregnant women and midwives.

\subsection{Participants}

Participants were a convenience sample of pregnant women presenting for antenatal care (ANC) at the hospital 
outpatient clinic who: 1) were at least 18 years of age, 2) did not need emergent medical attention, and 3) had at least one prior successful delivery. Women were told about the study by hospital staff and were approached by a local female nurse-translator who then invited participation following their ANC exam. All practicing midwives at the hospital were invited to participate. A total of ten women and seven midwives were interviewed at length.

\subsection{Consent Process and Data Collection}

All interviews were conducted face-to-face in a private area near the ANC clinic. Interviewees were taken through a short informed consent process in English and Twi (one of the dominant languages in Ghana) and were provided with a summary sheet that provided the researchers' contact information. Participants were reminded that their participation was voluntary, they could stop any time, and they could skip any questions they preferred not to answer. They were also reminded that no identifying information would be recorded in their data record.

All study-related documents, including the consent form, and the study were reviewed and approved or exempted from ongoing review by the Institutional Review Boards at the University of Michigan and the University of Ghana.

Upon completion of the consent process, the women and midwives participated in a 45 - 60 minute semistructured interview.

For midwives, the interview guide asked questions about routine deliveries, challenges they face during more complicated deliveries, experiences they have had with difficult patients, situations where they or others have raised their voices or hit a laboring woman, and behaviors that they judge to be acceptable and unacceptable during labor and delivery. For women, the interview guide asked about previous deliveries, experiences they have had with midwives, expectations for treatment during labor and delivery, and behaviors that they judge to be acceptable or unacceptable during labor and delivery.

All interviews were conducted in English with the help of the nurse-translator, and all interviews were audio-recorded. Additional handwritten notes were taken on the interview guides.

\subsection{Data Analysis}

Each interview was transcribed verbatim with identifying information excluded. All transcripts were entered into NVivo 9.0. Two of the authors (JY, CM) reviewed the transcripts and identified a preliminary coding structure, documented through the use of a codebook. The codebook described each code, what it included, and what it did not include. It also illustrated the hierarchies within codes, such as the "parent" and "child" nodes in NVivo. All transcripts were coded according to the codebook. The two authors met periodically to revisit the coding process, revise any definitions requiring alteration, and discuss any newly emerging codes. Any ambiguity in coding was discussed until consensus was reached.

Interviews were examined with a specific eye toward identifying the types of maltreatment reported, the frequency of such reports, the perceived severity, and attitudes toward maltreatment. In the midwife interviews, particular attention was paid to identifying perceived root causes.

Dominant themes were identified separately within the midwife and maternal interviews. Themes were compared to identify similarities and differences. All data were analyzed using NVivo 9.0 for Windows.

\section{Findings}

A total of ten women and seven midwives were interviewed. All participants were Ghanaian. See Table 1 below for demographic information.

Participants, including both midwives and women, acknowledged the common practice of maltreatment during labor and delivery. Types of maltreatment reported ranged from midwives yelling, screaming, hitting, slapping, humiliating, and neglecting women. There were also rumored accounts of caning; however none of the participants had seen this first-hand. In addition, most shared anecdotal stories about friends and relatives who faced maltreatment during their labor and delivery as well.

\subsection{Situations That Precipitate Abuse}

When asked about root causes of abuse, women and midwives told similar stories. Both types of respondents 
Table 1. Demographic information.

\begin{tabular}{ccc}
\hline & \multicolumn{2}{c}{ Demographic Information } \\
\cline { 2 - 3 } & Midwives & Women \\
\hline Sample N & 7 & 10 \\
Mean Age & 54.3 & 26.7 \\
\% with (4+) Children & $85 \%$ & $40 \%$ \\
\% Delivered with TBA in Past & 0 & $50 \%$ \\
\% Delivered in Facility in Past & $100 \%$ & $80 \%$ \\
Years of Experience & 13.3 & N/A \\
\hline
\end{tabular}

described a common predicament where women in the second stage of labor refuse to push. By not pushing, women are putting themselves and their babies at a higher risk of complications and even death. Midwives report that part of their job is to help women avoid complications and minimize the likelihood of a bad outcome, not only in the best interest of the mother and baby, but also because bad outcomes reflect poorly on the midwives. As a result, both midwives and women say it can be appropriate-even necessary-for midwives to yell or hit in an effort to motivate pushing and thus ensure a healthier outcome.

“At times when... you can see the baby is coming and you ask the mother to push she won't push. During that time, if you don't raise your voice a little you may lose the baby. So you have to raise your voice at the mother so that she will be active and push and will get the baby out.” (55-year-old midwife with 4 children). "[She says] that it is right for the midwife to hit the women because if something happens to the baby, they will say it is the midwife's fault.” (33-year-old woman with 2 children).

Respondents went so far as to say that midwives have the right to shout at women or hit them in the name of delivering a healthy baby.

"The midwife has the right to shout at the women and... cane the women... because you have to push and you are not pushing." (37-year-old woman with 6 children).

"[If] the midwife has to scream at you for you to give birth, fine. If she also hits you a little for you to... push the baby, fine... In order to bring the baby out alive.” (37-year-old woman with 6 children).

Another situation that precipitated maltreatment was when midwives feared that women were engaging in behavior that was not sanitary and thus put themselves or their babies at risk of infection. For example, women might squat on the floor during labor, sometimes defecating before delivering their baby directly onto the floor. Others might arrive at the hospital without necessary hygienic supplies (such as soap, a sheet to deliver on, etc.) despite explicit instructions. When these rules are broken and an unsanitary delivery space is created, midwives felt the need to yell, hit, or otherwise discipline women.

"Because of infection that's why I need... [to] keep them on the couch. We explained to them so it's not hygienic." (55-year-old midwife with 4 children).

"Sometimes you are doing the best you can do to conduct the delivery, they will sit on the floor, so before you come, she has flood the whole floor with feces and toilet, blood. That is when I will shout, the midwife will shout on you, because the midwife will [have to] clean all the mess." (51-year-old midwife with 2 children).

\subsection{Not All Maltreatment Is Acceptable}

Midwives and mothers in this study reported that some types of maltreatment are indicative of being a "bad midwife" - such as neglecting pregnant women when they are in need.

"A bad [mid] wife realistically is when a patient is in second stage and they call her, and you refuse to attend to her... If she calls you... midwife hey, you have to go." (51-year-old midwife with 2 children).

"Some [midwives] also, they ignore the women. They come later, they are either talking on their phone or they are watching TV, they don't have time for you. They allow you to be in pain. Some of the women even give birth on their own after they have called the midwife. Also they ask why didn't you call me when 
you were about to give birth, while they are just sitting there watching TV?” (26-year-old woman with 2 children).

Yet midwives pointed out that neglect is often a result of human resources challenges rather than the qualities of the midwives.

"Because we lack a lot of midwives, so that makes it difficult. So that means what two to three midwives might do, one single midwife will have to do... We are not enough.” (57-year-old midwife with 4 children). "They (the women) always want the midwife to be on their side when they are in labor. And there are only so many midwives on duty... That is why... we can't stand by the patient until the time she delivers." (56-year-old midwife with 4 children).

\subsection{Is Maltreatment Reciprocal?}

Respondents indicated that when in labor, women sometimes release their pain by yelling, kicking, or hitting the midwives attending their deliveries. This sort of behavior could be seen as maltreatment on the part of patients towards midwives.

One midwife described a laboring woman coming down the end of the bed and then intentionally kicking her in the mouth. "And then I could see there was blood coming." (51-year-old midwife with 2 children). Another midwife described a woman pushing against her abdomen hard enough that she felt like she was being kicked.

“They are so naughty that you shout on them, some like, look what you have done to me?” (51-year-old midwife with 2 children).

\subsection{Overarching Themes}

In addition to the broad themes described above, two overarching themes emerged from the data. They include: 1) The interaction between midwives and their patients is analogous to a mother/daughter relationship, including both a knowledge imbalance and the need for disciplinary action when necessary; and 2) Midwives feel a strong sense of accountability and responsibility for the labor and delivery outcomes.

\subsubsection{Interaction Is Analogous to Mother-Daughter Relationship}

Most women and the midwives described the interaction between midwives and their patients as similar to a mother/daughter relationship. Within that context, a knowledge imbalance was to be expected, and disciplinary action was considered to be acceptable if the midwife felt that it was needed, much like a mother would treat her daughter if she "misbehaved".

"Encourage her, talk to her, be friendly with her. If you are very close to the patient... I think, she will not be naughty. Talk to her friendly, as a mother or a sister, hey this is, you can do this, you can go like this.” (51-year-old midwife with 2 children).

"When you hit, you know it's not right... You have to discipline her to do the right thing. So it's a kind of discipline that we are doing." (57-year-old midwife with 4 children).

"You might not be pushing enough, so they may hit you a little to push. ... She [the mother] said she would take it as if the midwife was her mom; that she is at home and she has done something bad and her mother has beaten her." (18-year-old woman with 1 child).

"The midwife shouldn't have hit her, she should have rather encouraged her, and pampered her as like she's pampering a child.” (38-year-old woman with 4 children).

Both midwives and women interviewed indicated that laboring mothers often don't know what is best for them, and midwives are justified in yelling or hitting to prevent them from behaving in ways that are harmful to themselves during labor. As described earlier, the dominant examples of this surround knowing when to push, pushing appropriately, and maintaining a hygienic delivery.

\subsubsection{Midwives Are Ultimately Accountable for the Labor Outcome}

Many midwives reported that they feel personally responsible for the outcome of the labor, including any complications or deaths. Because of this weight of responsibility, midwives also reported feeling as though they 
needed to do "whatever it takes" to help mothers deliver safely. Midwives reported that it was better for a mother to be upset with them for how they were treated during delivery, but go home with a live child than for the midwives to be gentle with mothers and have them end up with a stillbirth.

"If you don't shout on her, she will relax and the baby will die and she will call your name... the midwife who has killed my baby. That name we don't want to hear it so we always shout on them to push to get a live baby... because our goal is to have healthy mother and live baby.” (55-year-old midwife with 3 children).

"Every possibility that you do for the person to get their baby, you should do it." (55-year-old midwife with 4 children).

\section{Discussion}

This study illustrates the complexity of the issue of maltreatment during labor and delivery. Both practicing midwives and pregnant women reported that maltreatment is most likely to occur in situations where the mother is not behaving in a way that the midwife perceives as beneficial to mother or baby, and in such cases, hitting, slapping or yelling at a woman in labor is justified. This study also found that midwives and women see their relationship as similar to one of a mother and daughter, including the associated knowledge imbalance and the need for occasional discipline. In addition, midwives reported a strong sense of accountability and responsibility for delivery outcomes, which they felt justified doing "whatever it takes” to get a laboring woman to push when appropriate or behave in a manner that facilitates positive outcomes.

This study expands upon existing studies of maltreatment in several important ways. While we recorded detailed descriptions of maltreatment reported by a variety of stakeholders in another region in Ghana, previous research did not address the question of why such behavior persisted [6]. Nor has the "why” been addressed in other studies documenting or alluding to the issue of maltreatment in Ghana [9]-[11], Nigeria [12]-[14], Swaziland [15] [16], Tanzania [17] [18], and Uganda [19]. The present study suggests there are certain situations that may serve as triggers for maltreatment, during which midwives feel as though the best way to obtain compliance from a laboring woman is to yell at or hit her. It also suggests that maltreatment may arise out of midwives' sense of maternal responsibility for the laboring women in their charge. Their sense of responsibility to both women and their babies, combined with few alternative strategies for intervention, results in harsh treatment in the name of encouraging a safe delivery.

These findings are slightly different from Abraham, Jewkes, and Mvo's study of midwives in South Africa, which found that although midwives are indeed seeking to control patient behavior, midwives in their setting used violence and maltreatment as a way to establish and maintain social distance between themselves and their clients [7]. Maintaining social distance was not the primary motivator in our sample-midwives genuinely seemed motivated by the desire to see a positive birth outcome and avoid being blamed for a negative outcome. Further research is warranted to determine whether/when given alternative strategies to influence mothers' behaviors, midwives would still rely upon hitting, yelling, and otherwise maltreating laboring women.

This study has several strengths. First, it included the voice of the midwives themselves, who have rarely been included in previous studies examining the issue of patient maltreatment. The midwives in this study vary widely in age, training, and demographic characteristics, a diversity that was confirmed by the breadth of insights identified in our data. Secondly, all of the pregnant women interviewed had at least one prior successful delivery, thus ensuring they were able to speak from prior delivery experience, rather than relying on discussions of family and friends' experiences.

The limitations of our study include the relatively small sample size and the inclusion of only one rural hospital in our data collection protocol. Our interviews may have yielded further results had we interviewed midwives from a variety of healthcare settings and urban regions, however, this was an exploratory study designed to uncover thoughts and attitudes that we could use to inform small-scale programmatic efforts. Since we heard similar themes across nearly all respondents, we feel comfortable with the validity of the collected data. Another potential limitation of the study was the real-time translation between English and Twi during the questionnaire administration, which allows for the possibility that descriptors and nuances were lost in the translation. To combat this, one of the authors, who also served as translator during the interviews, assisted with verification of quotes.

The results of this study have important implications. Our data indicate that there may be "precipitating events” 
that trigger maltreatment which could be the target of intervention strategies. For example, all women presenting for antenatal care could be educated about the importance of appropriate and effective pushing during delivery. Women could also be educated about the need for hygienic delivery conditions, including discussing where to deliver to avoid the contamination associated with delivering on the labor and delivery floor. For those women accustomed to squatting for delivery at home who present to a facility, alternative locations to the general labor and delivery floor can be provided.

Our data also suggest that, absent increases in human resources, midwives could benefit from in-service education regarding problem-solving strategies for difficult patients who refuse to push or patients who are non-compliant during labor. It is possible that when given more resources to handle challenging situations, midwives may not resort to maltreatment to accomplish the desired end.

This study also suggests several areas where further research is warranted. Studies with larger sample sizes that include providers in multiple settings could uncover dynamics that differ by setting. It is also possible that research including newly trained midwives, compared to those who have been practicing for many years, may uncover significant differences. Perhaps the most promising area for further inquiry is the potential for interventions to make lasting changes in the experiences during labor and delivery. Intervention research is an important next step to move beyond describing well-documented problems.

In summary, this study sheds light on a topic that is not well-understood: maltreatment of women during labor and delivery in rural Africa. Our data indicate that midwives perceive themselves to be acting in women's best interest, and such motivations may serve as important drivers in programmatic efforts to improve the care women receive.

\section{Conflict of Interest}

The authors have no conflicts of interest, financial or otherwise, to disclose.

\section{Funding Acknowledgements}

This study was supported by Grant Number T37 MD001425-15, from the National Center of Minority Health \& Health Disparities, National Institutes of Health and administered by the Center for Human Growth \& Development of the University of Michigan.

\section{References}

[1] Lozano, R., Wang, H., Foreman, K.J., Rajaratnam, J.K., Naghavi, M., Marcus, J.R., Dwyer-Lindgren, L., Lofgren ,K.T., Phillips, D., Atkinson, C., Lopez, A.D. and Murray, C.J. (2011) Progress towards Millennium Development Goals 4 and 5 on Maternal and Child Mortality: An Updated Systematic Analysis. The Lancet, 378, 1139-1165. http://dx.doi.org/10.1016/S0140-6736(11)61337-8

[2] Friberg, I.K., Kinney, M.V., Lawn, J.E., Kerber, K.J., Odubanjo, M.O., et al. (2010) Sub-Saharan Africa’s Mothers, Newborns, and Children: How Many Lives Could Be Saved with Targeted Health Interventions? PLoS Medicine, 7, e1000295. http://dx.doi.org/10.1371/journal.pmed.1000295

[3] Campbell, O.M.R. and Graham, W.J. (2006) Getting On With What Works. The Lancet, 368, 1284-1299. http://dx.doi.org/10.1016/S0140-6736(06)69381-1

[4] Ghana Statistical Service (GSS), Ghana Health Service (GHS), and ICF Macro (2009) Ghana Demographic and Health Survey 2008. GSS, GHS, and ICF Macro, Accra.

[5] Crissman, H., Engmann, C., Adanu, R.M., Crespo, K., Nimako, D. and Moyer, C.A. (2013) Shifting Norms: Pregnant Women's Increasingly Positive Perspective on Facility Delivery in Rural Ghana. African Journal of Reproductive Health, 17, 15-26.

[6] Moyer, C.A., Adongo, P.B., Aborigo, R.A., Hodgson, A., Engmann, C.M. and Devries, R. (2013) "It's Up to the Woman's People”: How Social Factors Influence Facility-Based Delivery in Rural Northern Ghana. Maternal and Child Health Journal, in press.

[7] Abrahams, N., Jewkes, R. and Mvo, Z. (1998) Why Do Nurses Abuse Patients? Reflections from South African Obstetric Services. Social Science \& Medicine, 47, 1781-1795. http://dx.doi.org/10.1016/S0277-9536(98)00240-8

[8] Moyer, C., Aborigo, R., Logonia, G., Affah, G., Rominski, S., Adongo, P., Williams, J. and Hodgson, A. (2012) Clean Delivery Practices in Rural Northern Ghana: A Qualitative Study of Community and Provider Knowledge, Attitudes, and Beliefs. BMC Pregnancy and Childbirth, 12, 50. http://dx.doi.org/10.1186/1471-2393-12-50 
[9] D’Ambruoso, L., Abbey, M. and Hussein, J. (2005) Please Understand When I Cry Out in Pain: Women's Accounts of Maternity Services during Labour and Delivery in Ghana. BMC Public Health, 5, 140. http://dx.doi.org/10.1186/1471-2458-5-140

[10] Mills, S. and Bertrand, J. (2005) Use of Health Professionals for Obstetric Care in Northern Ghana. Studies in Family Planning, 36, 45-56. http://dx.doi.org/10.1111/j.1728-4465.2005.00040.x

[11] Bazzano, A.N., Kirkwood, B., Tawiah-Agyemang, C., Owusu-Agyei, S. and Adongo, P. (2008) Social Costs of Skilled Attendance at Birth in Rural Ghana. International Journal of Gynaecology and Obstetrics: The Official Organ of the International Federation of Gynaecology and Obstetrics, 102, 91-94. http://dx.doi.org/10.1016/j.ijgo.2008.02.004

[12] Asuquo, E.E.J., Etuk, S.J. and Duke, F. (2000) Staff Attitude as a Barrier to the Utilization of University of Calabar Teaching Hospital for Obstetric Care. African Journal of Reproductive Health, 4, 69-73. http://dx.doi.org/10.2307/3583450

[13] Ejembi, C.L., Atli-Muaza, M., Chirdan, O., Ezeh, H.O. and Sheidu, S. (2004) Utilization of Maternal Health Services by Rural Hausa Women in Zaria Environs, Northern Nigeria: Has Primary Health Care Made a Difference? Journal of Community Medicine and Primary Health Care, 16, 47-54.

[14] Onah, H.E., Ikeako, L.C. and Iloabachie, G.C. (2006) Factors Associated with the Use of Maternity Services in Enugu, Southeastern Nigeria. Social Science \& Medicine, 63, 1870-1878. http://dx.doi.org/10.1016/j.socscimed.2006.04.019

[15] Uyirwoth, G.P., Itsweng, M.D., Mpai, S., Nchabeleng, E. and Nkoane, H. (1996) Obstetrics Service Utilisation by the Community in Lebowa, Northern Transvaal. East African Medical Journal, 73, 91-94.

[16] Thwala, S.B., Jones, L.K. and Holroyd, E. (2011) Swaziland Rural Maternal Care: Ethnography of the Interface of Custom and Biomedicine. International Journal of Nursing Practice, 17, 93-101. http://dx.doi.org/10.1111/j.1440-172X.2010.01911.x

[17] Kruk, M.E., Paczkowski, M., Mbaruku, G., de Pinho, H. and Galea, S. (2009) Women’s Preferences for Place of Delivery in Rural Tanzania: A Population-Based Discrete Choice Experiment. American Journal of Public Health, 99, 1666-1672. http://dx.doi.org/10.2105/AJPH.2008.146209

[18] Spangler, S.A. and Bloom, S.S. (2010) Use of Biomedical Obstetric Care in Rural Tanzania: The Role of Social and Material Inequalities. Social Science \& Medicine, 71, 760-768. http://dx.doi.org/10.1016/j.socscimed.2010.05.025

[19] Kyomuhendo, G.B. (2003) Low Use of Rural Maternity Services in Uganda: Impact of Women's Status, Traditional Beliefs and Limited Resources. Reproductive Health Matters, 11, 16-26. http://dx.doi.org/10.1016/S0968-8080(03)02176-1 